\title{
USE OF VIRTUAL REALITY FOR THE THERAPY OF CHILDREN WITH SOCIAL ANXIETY DISORDER
}

\author{
Ivan Kovar
}
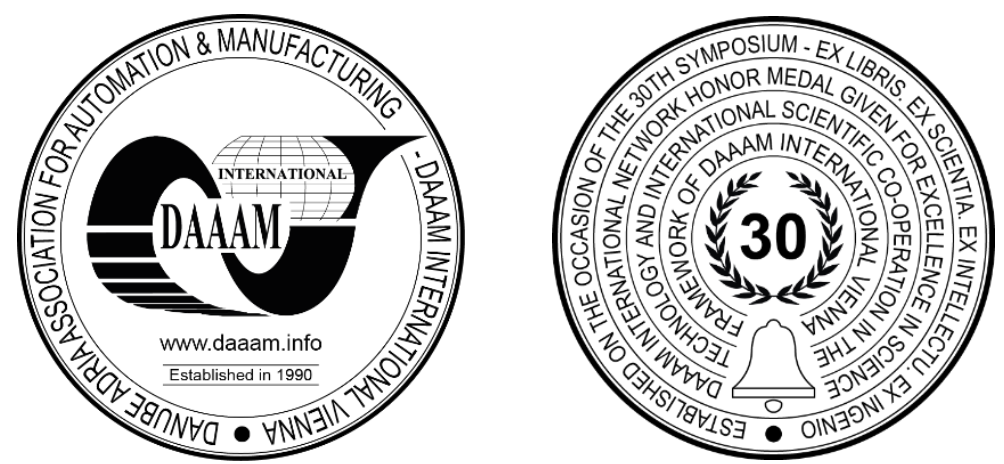

This Publication has to be referred as: Kovar, I[van] (2020). Use of Virtual Reality for the Therapy of Children with Social Anxiety Disorder, Proceedings of the 31st DAAAM International Symposium, pp.0550-0554, B. Katalinic (Ed.), Published by DAAAM International, ISBN 978-3-902734-29-7, ISSN 1726-9679, Vienna, Austria DOI: $10.2507 / 31$ st.daaam.proceedings.076

\begin{abstract}
The goal of this paper is to analyze the influence of virtual reality in psychological therapy of children with a social anxiety disorder. Many children suffer from this disorder during their lives. At the beginning of the paper, there is an explanation of social anxiety disorder and a theoretical description of a virtual reality device. The main part of the paper deals with the research itself which includes 6 months of intervention with 4 children who suffer from social anxiety disorder. The aim of the article is to find out whether it is possible to improve the mental health status of the investigated children through the purposeful help of virtual reality. The results of our findings show that with appropriate virtual reality treatment it can be achieved a reduction in depression and anxiety levels which can be seen in gained numbers from the psychological anxiety tests. Discussion and evaluation of the research are included.
\end{abstract}

Keywords: virtual reality; modern technologies; social anxiety; social phobia; anxiety disorder.

\section{Introduction}

The article deals with a topic of the use of VR (virtual reality) during CBT (cognitive behavioral therapy) as a tool to help children suffering from SAD (social anxiety disorder). SAD is an intense anxiety of fear of being judged, rejected, or negatively evaluated by others. People with this problem may worry about being viewed as stupid, boring or look visibly anxious [1]. People suffering from SAD often try to avoid social or performance situations and if it is not possible to avoid these situations, they feel extremely distressed and anxious. Many patients with SAD experience also physical symptoms like for example high heart rate, sweating or nausea [2]. Even if they know that their fear is unreasonable, they often feel vulnerable against the power of their disorder. There are two main types of SAD. The first one focuses on performance, with children worrying about things like speaking in public or trying out for a team. The second one includes social situations in general like for example eating in public, going to school, using public toilets or meeting people [3]. $\mathrm{SAD}$ is one of the most common psychiatric disorder of children with a lifetime prevalence of between $7-13 \%$ on the European continent [4]. Conclusions from different researches show that treatment of SAD is not optimal and often the use of mood stabilizers or anxiety medications is the main way how to deal with this serious problem [5]. There are already some research papers where the positive impact of VR in psychological therapy of people is indicated. 
For example, the use of VR in CBT of pensioners with communications disorders was already explored and there are provable positive effects on the mental health of patients [6]. SAD affects mostly adolescents, although it can also begin in early childhood, so we focus on children at a young age in our research. Undiagnosed and untreated SAD can lead to isolation, depression and even suicides [7].

VR can be explained as an electronic system that produces an artificially generated 3D made-up environment [8]. For our research, the VR unit Samsung Gear VR was used to create a 3D environment. Samsung Gear VR headset uses the smartphone Samsung Galaxy S7 Edge to calculate the virtual environment. VR device can be seen in Fig. 1. This device provides an affordable solution for creating a VR environment. This technology transfers users to a virtual environment through the power computing capacity of a smartphone. Compared to other VR environments, there is no special display and the phone screen is used as the stereoscopic display. A hand controller can be used for more interactive options. [9]

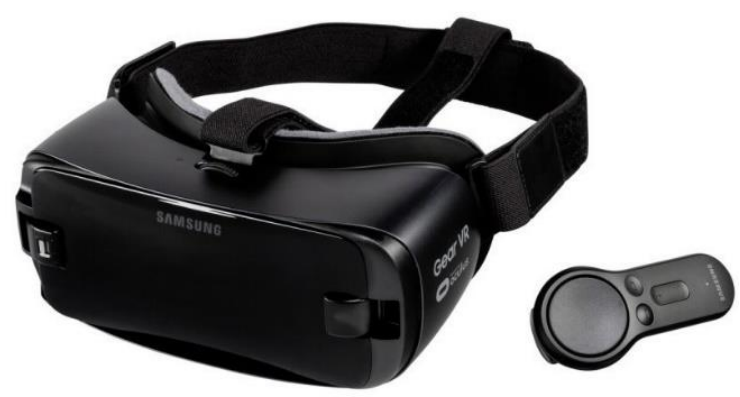

Fig. 1. Samsung Gear VR

\section{Description of the research}

The aim of this research is to train children in effectively managing situations they are afraid of, systematically increasing positive thinking and weakening negative mindsets to help them to enjoy a better-quality life. It would be a big success to help them live in a good mood and peacefully without the necessity to use antipsychotics. The main goal is to determine if it is possible to help the children with their mental health conditions with the use of VR affected psychological therapy. The basic data of four children who suffer from SAD were collected and can be seen in Table 1 . The research lasted six months, from November 2019 to April 2020 and all investigated children were exposed to VR affected psychological CBT. At the start of the analysis, we talked independently to all the children and their parents and received more detailed information about their life situation, family, school, various worries and mental health problems.

\begin{tabular}{|c|c|c|c|c|}
\hline & child 1. & child 2. & child 3. & child 4. \\
\hline Gender & male & female & female & male \\
\hline Age & 12 & 10 & 12 & 11 \\
\hline Medication & yes & yes & yes & yes \\
\hline $\begin{array}{c}\text { Approximate year in which they first time } \\
\text { experienced SAD }\end{array}$ & 2017 & 2019 & 2015 & 2017 \\
\hline
\end{tabular}

Table 1. General personal data of the investigated children

There were 24 psychological sessions with each investigated child. During the six months research period, three hours psychological session with each investigated child was held every week. The structure of all the psychological sessions was always the same. All the children, together with the help of their parents filled in two well-known psychological anxiety tests (Social Avoidance and Distress Scale, Metacognition Questionnaire-30) at the beginning of each session. After these tests, there was following VR affected psychological CBT. The child 2. can be seen during her VR therapy in Fig. 2.

During this therapy, a unique $360^{\circ}$ VR video content was presented to the children with the use of VR headset. This unique $360^{\circ} \mathrm{VR}$ video content was recorded with the use of a professional $360^{\circ}$ camera Insta360 Pro. This multimedia content was created and designed individually for every child according to the child's diagnose and the requirement to help to calm down, slow down breathing, focus and relax. For better multimedia experience, the whole psychological therapy was supplemented with 5.1 surround sound. Every time when the therapeutic session finished, there was a thirty minutes long relaxation phase to have fun and get rid of the tension. This last phase was designed to help children with relaxation and easing their stress and nerves. The children could choose some entertainment applications, for example games, simulations, or any VR cartoon fairy tale. Once per every month, a psychologist and a general practitioner were visited by the children to consult their psychological status, measure the basic physiological body functions, progress and other issues related to this research. The effect of VR affected psychological CBT on the mental state of the children was checked and the results were measured. In Fig. 3. can be seen the child 1. during his VR therapy while he was going through an exciting adventurous situation. 


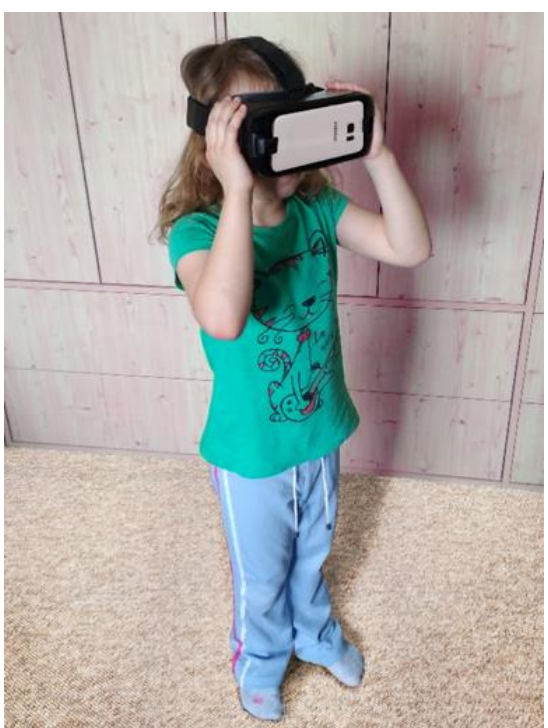

Fig. 2. Child 2. during her VR CBT session

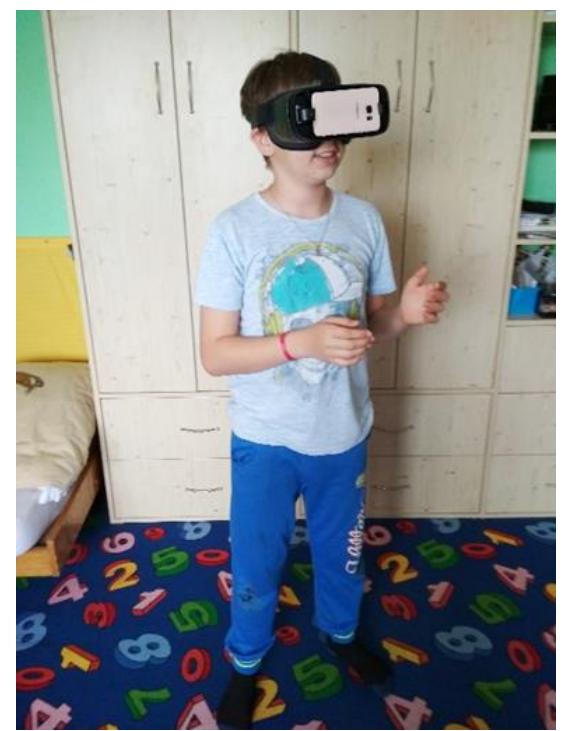

Fig. 3. Child 1. during VR affected psychotherapy

\section{Results and discussion}

The psychological conditions of examined children were inspected with the use of two well-known psychological tests.

\subsection{Social Avoidance and Distress Scale (SADS)}

Every statement of this test is linked with a specific point of SAD. Children have to answer honestly whatever the question is false or true according to them and if they are not sure, they should pick the answer which describes better their mood in the present moment. It is important not to think for a long time and choose the response which describes better their feelings at the first sign. The total score can be from 28 to 0 points, where a higher score means a higher level of SAD and this total score is based on counts of true/false responses. [10] The measurements of SADS test are visualized in Fig. 4.

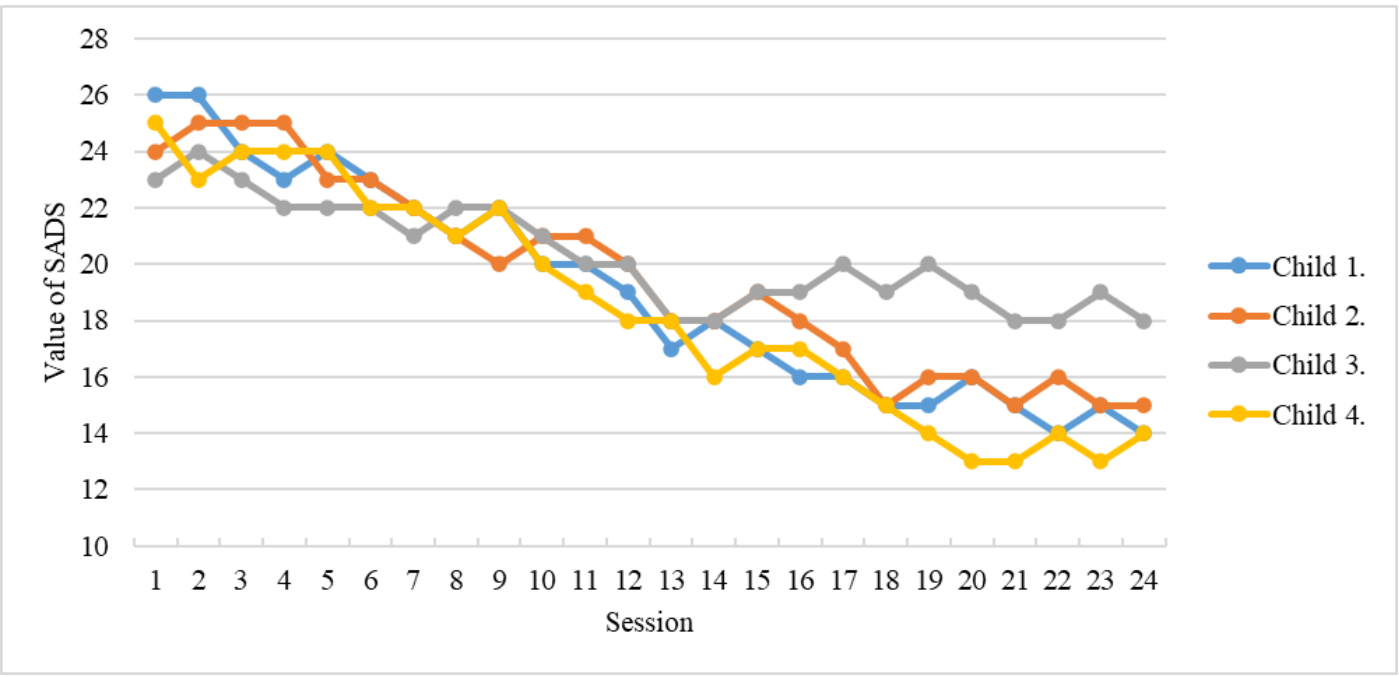

Fig. 4. Data gained from the SADS test

\subsection{Metacognition Questionnaire-30 (MCQ-30)}

It is a self-report test that assesses metacognitive beliefs. The factors are cognitive self-consciousness, the need to control thoughts, cognitive confidence, positive beliefs about worry, negative beliefs about uncontrollability and danger. It may boost pathological concerns if there is poor metacognition. The total score for this test can be from the range of 120 to 30 points, where a higher score means a higher grade of incorrect metacognitions. [11] The results of MCQ-30 measurements are visualized in Fig. 5. 


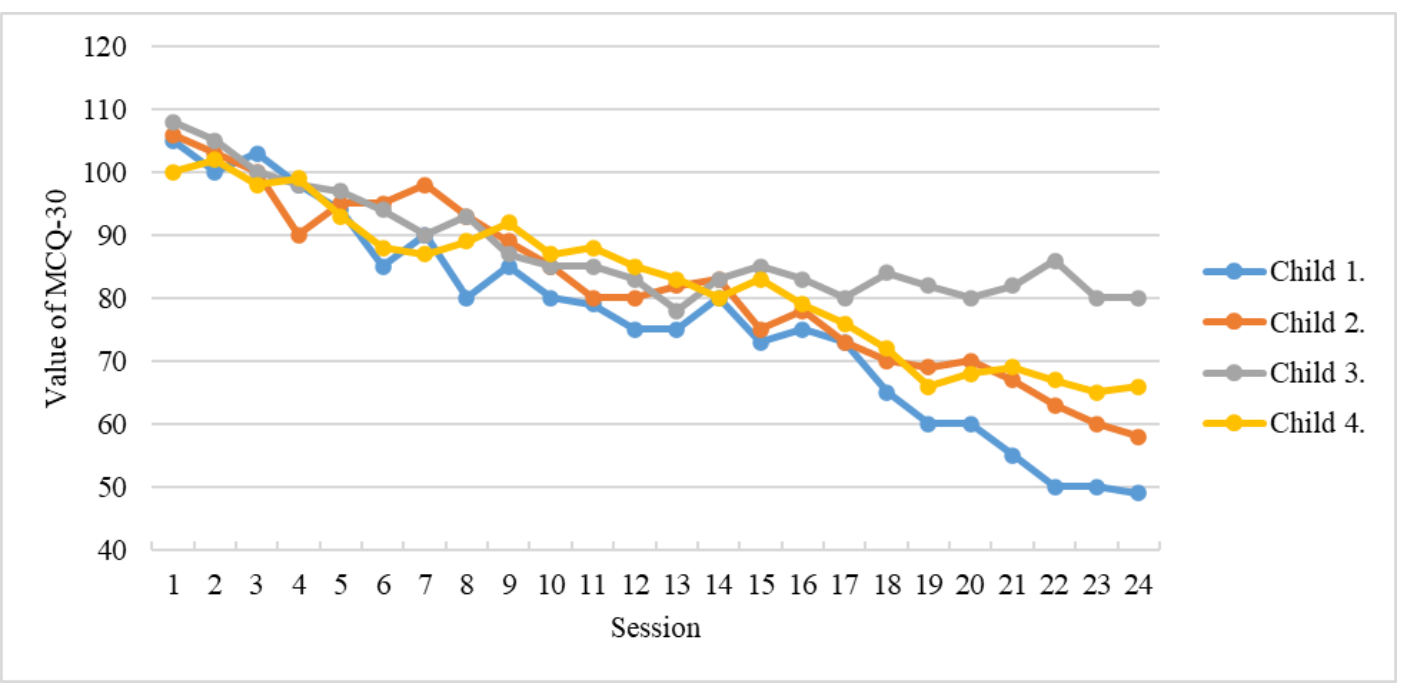

Fig. 5. Data gained from the MCQ-30 test

The results of our psychological tests (SADS and MCQ-30) show provable decreases in depression levels of investigated children. These results are expressed in quantity $\Delta$ which expresses the difference between results from tests measured on the first and the last session of the research. In SADS test, there were measured $\Delta$ child $1 .=12, \Delta$ child $2 .=$ 9, $\Delta$ child $3 .=5$ and $\Delta$ child $4 .=11$. In MCQ-30 test, there were measured $\Delta$ child $1 .=56, \Delta$ child $2 .=48, \Delta$ child $3 .=$ 28 and $\Delta$ child $4 .=34$.

\section{Conclusion}

The measured differences $\Delta$ in all the psychological tests show that the children who underwent VR supported CBT achieved a markedly better anxiety score than they had before the start of this research. The most resonating question of this paper was to answer if VR can be used as a tool to help children during CBT with the healing of SAD. The results of our psychological tests after the application of 6-month long intensive research intervention are promising because there are provable decreases in depression and anxiety levels. From the measured data, it can be deduced that the research had clinically positive change and shows that people suffering from SAD can use VR for visualization of situations where they can regularly and easily train how to deal with their disorder. If the ideas from the research to use VR in CBT were accepted and implemented in general, it could create a safe environment and physically painless form of the therapy for children with elements of entertainment.

The small sample of investigated children, short research period and VR headset with low resolution are definitely limitations of this paper. Although this research was done only with 4 children, it seems that VR can be used as a powerful tool in CBT. To be totally sure with the argument that VR has a clinically important role in dealing with SAD, it is relevant to make extended and much extensive research in which a bigger sample of respondents will participate, and more psychological tests will be investigated. The extended version of this research with 20 children, one-year research period, and the use of a more advanced VR headset is further planed. Based on our research and other research papers worldwide, it can be predicted that VR has a generally positive impact on human psychological health and use of the VR will be rapidly extended to more and more areas of human health. [12]

\section{Acknowledgments}

This paper was prepared with the support by grant no. IGA/CebiaTech/2020/005 from Internal Grant Agency of Tomas Bata University in Zlin.

\section{References}

[1] Jefferson, JW. (2001). Social Anxiety Disorder: More Than Just a Little Shyness. Prim Care Companion J Clin Psychiatry.(1):4-9. DOI:10.4088/pcc.v03n0102

[2] Schneier, F. \& Goldmark, J. (2015). Social Anxiety Disorder. Stein, Dan J. \& Vythilingum, B., ed. Anxiety Disorders and Gender. Cham: Springer International Publishing, 49-67. ISBN 978-3-319-13059-0. Available: DOI:10.1007/978-3-319-13060-6_3

[3] Hitchcock, CA.; Chavira, DA. \& Stein, MB. (2009). Recent findings in social phobia among children and adolescents. Isr J Psychiatry Relat Sci. 46(1). 
[4] Kim, HE.; Hong YJ.; Kim MK.; Jung YH.; Kyeong S. \& Kim JJ. (2017). Effectiveness of self-training using the mobile-based virtual reality program in patients with social anxiety disorder. Computers in Human Behavior, 73, 614-619. ISSN 07475632. Available: DOI:10.1016/j.chb.2017.04.017

[5] Williams, T.; Hattingh C.; Kariuki C.; Tromp SA.; Van Balkom A.; Ipser J. \& Stein DJ. (2017). Pharmacotherapy for social anxiety disorder (SAnD). Cochrane Database of Systematic Reviews. ISSN 14651858. Available: DOI:10.1002/14651858.CD001206.pub3

[6] Kovar, I. \& Musalek, M. (2018). Use of Virtual Reality for the Therapy of Pensioners with Communication Disorders, Proceedings of the 29th DAAAM International Symposium, pp.0811-0816, B. Katalinic (Ed.), Published by DAAAM International, ISBN 978-3-902734-20-4, ISSN 1726-9679, Vienna, Austria DOI: 10.2507/29th.daaam.proceedings. 117

[7] Kashdan, TB. \& HERBERT J. (2001). Social anxiety disorder in childhood and adolescence: current status and future directions. Clinical Child and Family Psychology Review. 4(1), 37-61. ISSN 10964037. Available: DOI:10.1023/A:1009576610507

[8] Deac, GC.; Georgescu, CN.; Popa, CL.; Ghinea, M \& Cotet, CE. (2018). Virtual Reality Exhibition Platform, Proceedings of the 29th DAAAM International Symposium, pp.0232-0236, B. Katalinic (Ed.), Published by DAAAM International, ISBN 978-3-902734-20-4, ISSN 1726-9679, Vienna, Austria DOI: 10.2507/29th.daaam.proceedings.033

[9] Qadri, M.; Hussain, MS.; Jawed, S. \& Iftikhar, SA. (2019). Virtual Tourism Using Samsung Gear VR Headset, 2019 International Conference on Information Science and Communication Technology (ICISCT), Karachi, Pakistan, pp. 1-10, DOI: 10.1109/CISCT.2019.8777410.

[10] Sobanski, J.; Klasa, K \& Rutkowski, K. (2013). Social Avoidance and Distress Scale (SAD) and Fear of Negative Evaluation Scale (FNE) - reliability and the preliminary assessment of validity. Psychiatr Pol. 47(4), 691-703.

[11] Wells, A. \& Cartwright-Hatton, S. (2004). A short form of the metacognition's questionnaire: properties of the MCQ-30. Behaviour Research and Therapy. 42(4), 385-396. DOI: 10.1016/S0005-7967(03)00147-5. ISSN 00057967.

[12] Botella, C.; Serrano, B.; Banos, R. \& Garcia-Palacios, A. (2015) Virtual reality exposure-based therapy for the treatment of post-traumatic stress disorder: a review of its efficacy, the adequacy of the treatment protocol, and its acceptability. Neuropsychiatric Disease and Treatment. DOI: 10.2147/NDT.S89542. ISSN 1178-2021. 